Portland State University

PDXScholar

1982

\title{
The relationship of brain hemisphere orientation to WISC-R subscale scores
}

Robin Diane Thomas Hayden

Portland State University

Follow this and additional works at: https://pdxscholar.library.pdx.edu/open_access_etds

Part of the Cognition and Perception Commons

Let us know how access to this document benefits you.

\section{Recommended Citation}

Hayden, Robin Diane Thomas, "The relationship of brain hemisphere orientation to WISC-R subscale scores" (1982). Dissertations and Theses. Paper 3321.

https://doi.org/10.15760/etd.3301

This Thesis is brought to you for free and open access. It has been accepted for inclusion in Dissertations and Theses by an authorized administrator of PDXScholar. Please contact us if we can make this document more accessible: pdxscholar@pdx.edu. 
AN ABSTRACT OF THE THESIS OF Robin Diane Thomas Hayden for the Master of Science in Psychology presented November 10, 1982.

Title: The Relationship of Brain Hemisphere Orientation to WISC-R Subscale Scores.

APPROVED BY MEMBERS OF THE THESIS COMMITTEE:

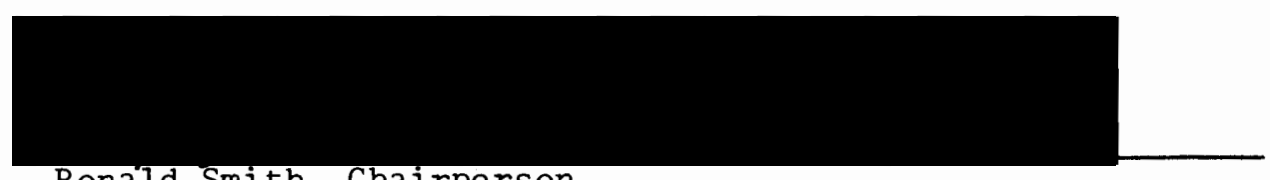

Ronald Smith, Chairperson
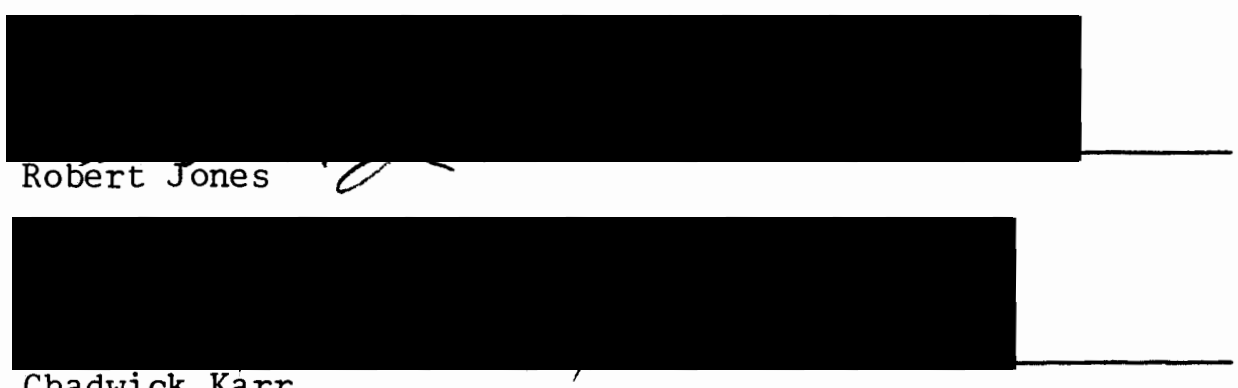

Because there is a growing amount of contradictory evidence concerning the relationship of WISC-R subscale scores to hemispheric orientation, the present study examined the validity of the WISC-R subscale scores as indicators of individual hemispheric orientation.

The present study hypothesized a significant relationship between Verbal-Performance scale score discrepancies and hemispheric orientation as assessed by conjugate lateral eye movements. This study also hypothesized that subjects with a right hemisphere orientation would score higher on the block design, picture completion, and object assembly subtests than would subjects with a left hemisphere orient- 
ation.

A total of 784 th-through 8 th-grade students were administered the Wechsler Intelligence Scale for Children--Revised. During testing, observations of each subject's eye movements were recorded. Twentyeight subjects were found to be hemispherically oriented. These 28 subjects were assigned to right or left hemisphere oriented groups.

When Verbal-Performance scale score differences and block design, object assembly, and picture completion scale scores were compared across groups, no significant relationships were found. Therefore, the two hypotheses were not supported. 
THE RELATIONSHIP OF BRAIN HEMISPHERE ORIENTATION TO WISC-R SUBSCALE SCORES

by

ROBIN DIANE THOMAS HAYDEN

A thesis submitted in partial fulfillment of the requirements for the degree of

\author{
MASTER OF SCIENCE \\ in \\ PSYCHOLOGY
}

Portland State University

1983 
TO THE OFFICE OF GRADUATE STUDIES AND RESEARCH:

The members of the Committee approve the thesis of

Robin Diane Thomas Hayden presented November 10, 1982.

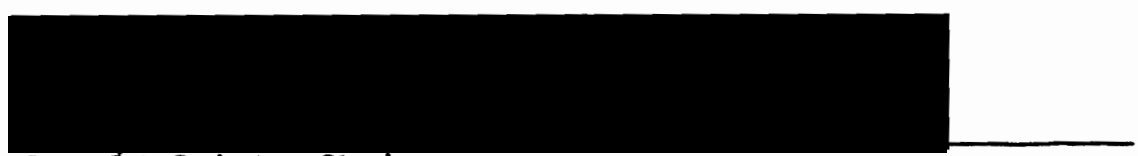

Ronald Smith, Chairperson
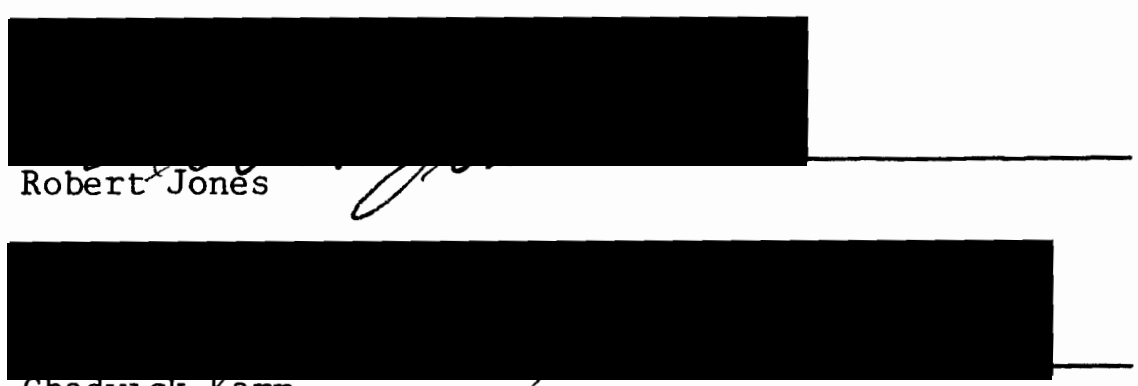

Chadwlck Karr

APPROVED :

David Wrench, Head, Department of Psychology

Stanley E. Rauch, Dean of Graduate Studies and Research 
TABLE OF CONTENTS

PAGE

LIST OF TABLES

CHAPTER

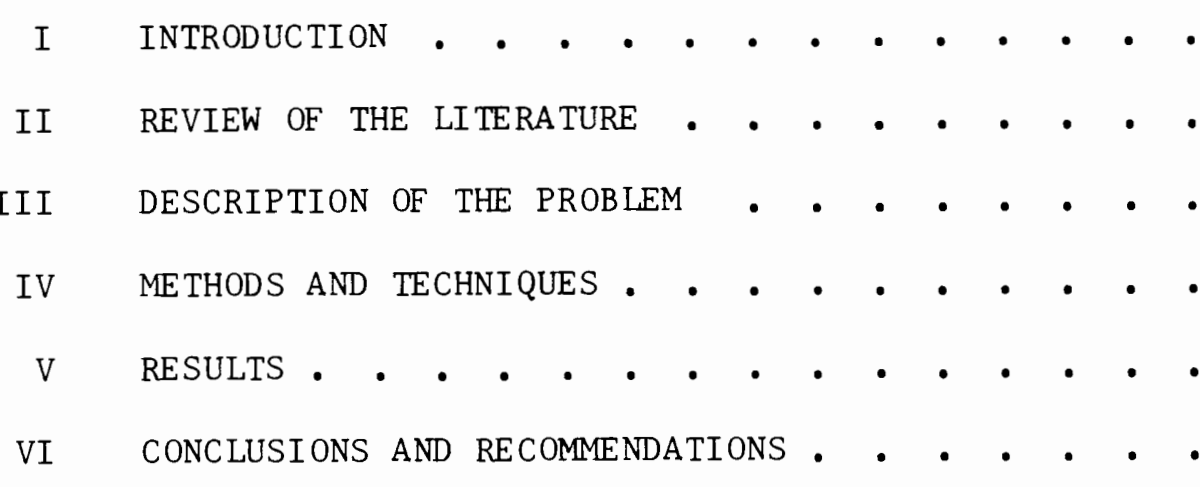

VI CONCLUSIONS AND RECOMMENDATIONS • • • • • • 


\section{LIST OF TABIES}

PAGE

TABLE

I Summary of Verbal-Performance Subscale Difference

Data and Analyses • • • . . . • • •

II Summary of Composite Data and Analyses for Object

Assembly, Block Design, and Picture Completion . •

II Summary of Picture Completion Data and Analyses • •

IV Summary of Block Design Data and Analyses • • • • 15

$\mathrm{V} \quad$ Summary of object Assembly Data and Analyses • • • 16

VI Distribution of Scale Scores . . . • . . - . 
CHAPTER I

INTRODUCTION

Discrepancies between IQ scores on the Verbal and Performance subscales of the Wechsler Intelligence Scale for Children--Revised (WISC-R) span a broad continuum from little or no difference to differences of 20 or more points (Kaufman, 1979a). These two subscales were designed to test two differing types of intelligence. The Verbal subscale tests linguistic abilities such as verbalizing general information and defining vocabulary words. The Performance subscale assesses visual and spatial abilities such as locating missing parts of a picture and assembling blocks to match a design (Kaufman, 1979a, 1979b).

Kaufman (1979b) points out that the WISC-R subscales were named and developed on "the content of each task, not the process required to solve each item correctly" (p. 99). The content, as opposed to process labelling, is an important distinction to bear in mind while reviewing research associating brain hemispheric specialization and the WISC-R subscales. Although typically the left hemisphere specializes in verbal tasks and the right in performance tasks, these are process distinctions, not content distinctions.

Kaufman (1979b) points out that some of the WISC-R subscale tasks involve hemispheric processes not largely associated with the labelling of the subscale. For example, although the Verbal subscale is mainly in the specialization realm of the left hemisphere, the arithmetic and 
digit span backward subtests of the Verbal subscale utilize some visualization processes which are within the specialization domain of the right hemisphere (see also: Bogen, 1969; Galin, 1974; Gazzaniga, 1970). Furthermore, only three of the six Performance subtests utilize the right hemispheric specialization processes to the exclusion of the left. The three Performance subtests utilizing exclusively right hemisphere specialization are block design, picture completion, and object assembly (Kaufman, 1979b, p. 99).

Despite the overlap of cognitive processes, the subscales have been shown to reflect accurately "the differential integrity of the two cerebral hemispheres in older children with learning disabilities" (Rourke \& Telegdy, 1971, p. 875), in younger children with learning disabilities (Rourke, Young, \& Flewelling, 1971), and hemiplegic children (Kershner \& King, 1974).

The conjugate lateral eye-movement phenomenon first described by Day (1964) has also been shown to reflect hemispheric activity (Bakan, 1971; Duke, 1968; Galin \& Ornstein, 1974; Kinsbourne, 1972; Weiten \& Etaugh, 1973). The conjugate lateral eye-movement phenomenon occurs when one has established eye contact with another and asks the other a question requiring thought; the other will avert his/her eyes right or left immediately after hearing the question. Before a subject can be proclaimed a right or left mover, the direction of eye movements must be at least $70 \%$ consistent as arbitrarily established by researchers in this area. A right mover is said to be left hemisphere oriented while a left mover is right hemisphere oriented (Bakan, 1971; Kinsbourne, 1972; Kocel, Galin, Ornstein, \& Merrin, 1972; Reynolds \& Kaufman, 1980). 
As the research comparing WISC-R subscale score differences and brain hemisphere orientation is contradictory, there is a need for conclusive evidence in this field. Since the conjugate lateral eyemovement phenomenon has been shown to reflect hemispheric activity, the present research compares WISC-R subscale score differences and conjugate lateral eye movement results to study directly the question of whether subscale scores show hemisphericity. 


\section{CHAPTER II}

\section{REVIEW OF THE LITERATURE}

Rourke and Telegdy (1971) found that "45 9- to 14-yr.-old [sic] right-handed boys with learning disabilities" (p. 875) had significantly higher Performance IQ's than Verbal IQ's on the WISC-R.

Kershner and King (1974) compared achieving hemiplegic children to normal children using the WISC and the Reitan-Indiana Neurological Tests. They found the right hemiplegic children were poorer in verbal intelligence than normal children and the left hemiplegic children were poorer in visuo-spatial or performance intelligence. These studies add support to the growing evidence that the WISC-R subscales are indicative of hemispheric functioning.

Contradictory evidence is available from Wener and Templer (1976) who attempted to replicate the Rourke and Telegdy study without success. Wener and Templer conclude that "WISC IQ Verbal-Performance discrepancy was not a good predictor of motor and psychomotor learning disabilities" (p. 125).

In light of this contradictory evidence it is appropriate to test directly the validity of subscale discrepancy in reflecting hemispheric activity or orientation. To carry out such a study, an accepted indicator of hemispheric orientation is required.

Day (1964) described an eye-movement phenomenon he had observed casually. Day observed that when asked a question, people tend to avert 
their eyes laterally. Day noted this movement to be consistent over time in individuals, and apparently related to basic personality differences and the experience of anxiety.

Duke (1968) undertook research to document Day's casual observations. Duke asked 53 undergraduates a series of 10 questions and observed each subject's dominant eye. He found that "subjects average making 86 percent of their lateral eye movements in the same direction" (p. 192). He also found eye dominance and sex were not related to eyemovement direction. However, males did tend to be more consistent in direction than females. Duke was able to support Day's observations that eye movements occur most frequently following reflective questions rather than simple fact questions.

Etaugh (1972) studied 89 college students for correlations between both handedness and sex and eye-movement consistency. She did not find any significant correlations, thus concluding eye movements are separate from handedness and sex.

Bakan and Strayer (1973) did a test-retest study on the consistency of eye-movement direction over time. They asked 34 subjects a set of 12 proverbs on two occasions separated by one to seven days. Testretest reliability "was .78 for all Ss, .72 for males, and .80 for females. Individuals are consistent over time in direction of such eye movements" (p. 429).

In a study of 40 right- and left-handed undergraduates, Kinsbourne (1972) found right handers to gaze to the right and left handers to be random in eye-movement direction. Kinsbourne states that his results suggest "the direction in which people look while thinking reflects the 
lateralization of the underlying cerebral activity" (p. 539). He also reports that the eye movements were so obvious that there was no cause for dispute between his two judges.

Bakan (1969) studied 46 undergraduates to explore the relationship between lateral eye movements and hypnotic susceptibility in terms of functional asymmetry of the brain. Bakan administered the Stanford Hypnotic Susceptibility Scale as well as a set of five questions for eye-movement observations to each subject. Forty-two of the 46 subjects were classifiable as right or left eye movers with an average of $85 \%$ of the subject's eye movements in the same direction. There were 24 left movers and 18 right movers in the Bakan study. Left movers were related with greater hypnotizability than were right movers. Bakan reports that "base level EEG alpha is related both to hypnotizability (London, Hart, \& Leibovitz, 1968; Nowlis \& Rhead, 1968) and laterality of eye-movements (Bakan \& Svorad, unpublished)" (p. 931) suggesting a positive relationship between EEG alpha which "is found in greater amounts and amplitude over the non-dominant [right] side of the brain" (p. 931) and left movers.

Kocel et al. (1972) asked 29 adult subjects two sets of 20 questions. One set of questions was designed to activate right hemisphere processes, e.g., "try to picture all the doors in your house and tell me how many door knobs there are" (p. 223), and a second set to activate left hemisphere processes, e.g., "define the word 'economics'" (p. 223). Each subject was asked a total of 40 questions. The right and left hemisphere activation questions were presented in a counterbalanced order. Eye-movement observations were made during questioning. 
Their results show that lateral eye-movement direction indicates contralateral hemispheric activation. They found subjects looked left when asked right hemisphere questions and right when asked left hemisphere questions. Also, Kocel et al. found consistency in their individual subject's eye-movement direction, thus confirming "individuals can be characterized as 'right movers' or 'left movers'" (p. 224).

Galin and Ornstein (1974) studied the reflective eye movements of 35 lawyers and ceramicists. The subjects were asked questions designed to evoke either verbal or spatial processing. The results confirmed that "verbal questions evoke more right movements than spatial questions" (p. 367). They also report that "asymmetry in reflective eye movement and in the EEG reflect the lateralization of verbal and spatial cognitive processes within subjects" (p. 368) i.e., eye movements were indicative of hemispheric orientation within subjects with consistently right movers being left hemisphere oriented and left movers being right hemisphere oriented whether or not the questions asked were most efficiently solved by the oriented hemisphere.

Weiten and Etaugh (1973) compared 20 consistent right movers to 20 consistent left movers on measures which utilized right or left hemisphere functions. They found $79.9 \%$ average eye-movement consistency within subjects, with no sex differences. They also found that right movers performed better on tasks emphasizing verbal and analytic skills than did left movers.

Reynolds and Kaufman (1980) studied lateral eye-movement behavior in 52 children, aged 2-11. They found the phenomenon present in 50 of 
the children with approximately half of the 50 , or 25 children, making $70 \%$ of their eye movements in the same direction allowing them to be considered right of left movers. The children were asked both spatial and verbal-analytic questions. The type of question was not shown to affect eye-movement directions. Reynolds and Kaufman state "consistent movement of the eyes to the left indicates right-brain activity and suggests a dominant right hemisphere . . [therefore $]$ a 'right-mover' conceivably has a dominant left hemisphere" (p. 1024). Reynolds and Kaufman explain that hemisphere dominance is reflective of the most relied upon style of thinking or processing rather than the hemisphere's specific functions.

In sum, researchers agree that although the type of question asked influences eye-movement direction, most subjects are at least $70 \%$ consistent in the direction of their eye movements. The researchers also agree that eye-movement direction indicates contralateral hemispheric activity and seems to denote a subject's most relied upon style of thinking be it verbal-analytic (left hemisphere) or spatial-holistic (right hemisphere). Conjugate lateral eye movements, therefore, will serve as an indicator of hemispheric orientation for the current study. 


\section{CHAPTER III}

\section{DESCRIPTION OF THE PROBLEM}

The present study was designed to determine the validity of the WISC-R subscales as an indicator of individual hemispheric orientation. The conjugate lateral eye-movement phenomenon at $70 \%$ consistency served as the basis for determining hemispheric orientation. Consistency of $70 \%$ is the typical although arbitrary criterion utilized in conjugate lateral eye-movement research.

The present study hypothesized there would be a significant relationship between Verbal-Performance scale score differences and hemispheric orientation as assessed by conjugate lateral eye movements. It was expected right hemisphere oriented subjects would have higher Performance than Verbal scale scores while left hemisphere oriented subjects would have higher Verbal than Performance scale scores as the Rourke and Telegdy (1971) and Kershner and King (1974) studies suggest. It was further hypothesized that right hemisphere orientation would relate to better performance on the block design, picture completion, and object assembly subtests than would left hemisphere orientation, as these subtests most unilaterally utilize the right hemisphere functions (Kaufman, 1979b). 
CHAPTER IV

ME THODS AND TECNHIQUE

SUBJECTS

Subjects were obtained from among students attending Riverdale School District in Portland, Oregon. Approximately 150 students constituting the enrollment of the fourth through eighth grades were given the opportunity to participate in the study. A total of 78 boys and girls between the ages of 8 and 14 years served as subjects. Of the 78 children, 28 demonstrated hemisphericity through conjugate lateral eye-movement observations and were assigned to groups accordingly.

\section{APPARATUS}

Each subject was administered the Wechsler Intelligence Scale for Children--Revised. Concurrently, each subject was observed for conjugate lateral eye movements.

\section{PROCEDURE}

The parents of the 150 students enrolled in Riverdale's fourth through eighth grades were sent letters briefly describing the study and requesting permission for their child's participation (see Appendix). All participating subjects were normal children, i.e., children without known histories of neurological dysfunctions.

The parents of 79 children granted permission for participation. 
The 79 children were then assigned to testing times and areas by their home-room teachers during school hours. The experimenter and two assistants conducted the testing and eye-movement observations of each child. Due to experimenter error, the WISC-R of one child was invalidated and the subject dropped from the experiment.

Preliminary testing was conducted to ascertain inter-rater reliability of eye-movement observations and to gain experience in doing the double task of observation and test administration. Inter-rater reliability was computed via Cohen's kappa for three administrations of a 12-item list of questions. Cohen's kappa ranged from $\underline{k}=.65$ to $\underline{k}=1.0$ or perfect agreement between observers. The mean agreement was $\underline{k}=.85$.

The children were informed they were helping the principal investigator with a paper for school. They were then told the experimenter would ask them some questions and have them do some tasks. Each child was asked to do his or her best while not worrying about possible wrong responses.

Each child was tested in a private room according to the WISC-R testing manual guidelines. The experimenter sat directly in front of the subject to insure subjects the freedom to look either right or left without distraction from the experimenter. The rooms were as free from visual and audio distractions as possible.

Observations of conjugate lateral eye movements were recorded during the testing process. The experimenter waited until the subject made eye contact before presenting the tasks in the WISC-R. The first eye movement within five seconds following the completion of the 
task presentation was then recorded. Experimenters recorded only obvious right or left moves, calling all other moves non-scorable. A subject was required to demonstrate at least $70 \%$ eye-movement direction consistency to be considered a right or left mover with contralateral hemispheric specialization.

Of the 78 subjects tested, 28 were consistent in eye-movement direction. They were assigned to two groups based on hemisphere orientation as assessed by consistent lateral eye movements. Left hemisphere oriented subjects totalled 19, 12 boys and 7 girls, and were labeled Group I $\left(G_{1}\right)$. Right hemisphere oriented subjects totalled 9, 1 boy and 8 girls, and were labeled Group $2\left(G_{2}\right)$.

Following completion of testing, the principal investigator scored each WISC-R protocol and compiled eye-movement observation data to assign hemispheric orientation. WISC-R's were double-checked by the principal investigator's thesis committee chairperson for scoring accuracy. The thesis committee chairperson's decisions were final in the scoring of the protocols. 


\section{CHAP TER V}

\section{RESULTS}

The subjects were divided into two groups according to hemispheric orientation as assessed by conjugate lateral eye movements (CLEM). Group 1 consisted of 19 left hemisphere oriented subjects and Group 2 consisted of 9 right hemisphere oriented subjects. Fifty of the 78 subjects tested did not demonstrate hemispheric orientation by percentage of CLEM. The data from these 50 subjects were grouped under the heading of "Other."

For each of the 28 hemispherically oriented subjects the scale scores for each subtest were summed for the Verbal and Performance subscales respectively. Differences between the two subscales were obtained, for each subject, by subtracting the Performance subscale score from the Verbal score and summing differences algebraically. Means and standard deviations were computed and are presented in Table I. A standard one-way analysis of variance (Bruning \& Kintz, 1977, pp. 24-27) was conducted on Verbal-Performance subscale differences for Group $1\left(G_{1}\right)$, Group $2\left(G_{2}\right)$ and 0 ther to determine if hemispheric orientation affected subscale score differences. The differences, presented in Table $I$, were not shown to be significant at the .10 alpha level. As the data from group Other is not related to the hypothesis which questions the relationship between hemispherically oriented subjects and subscale differences, a $\underline{t}$ test for a difference between two independent 
means was conducted on subscale score differences for $G_{1}$ and $G_{2}$. The differences as shown in Table I were not significant at the .10 alpha level.

\section{TABLE I}

SUMMARY OF VERBAL-PERFORMANCE SUBSCALE

DIFFERENCE DATA AND ANALYSES

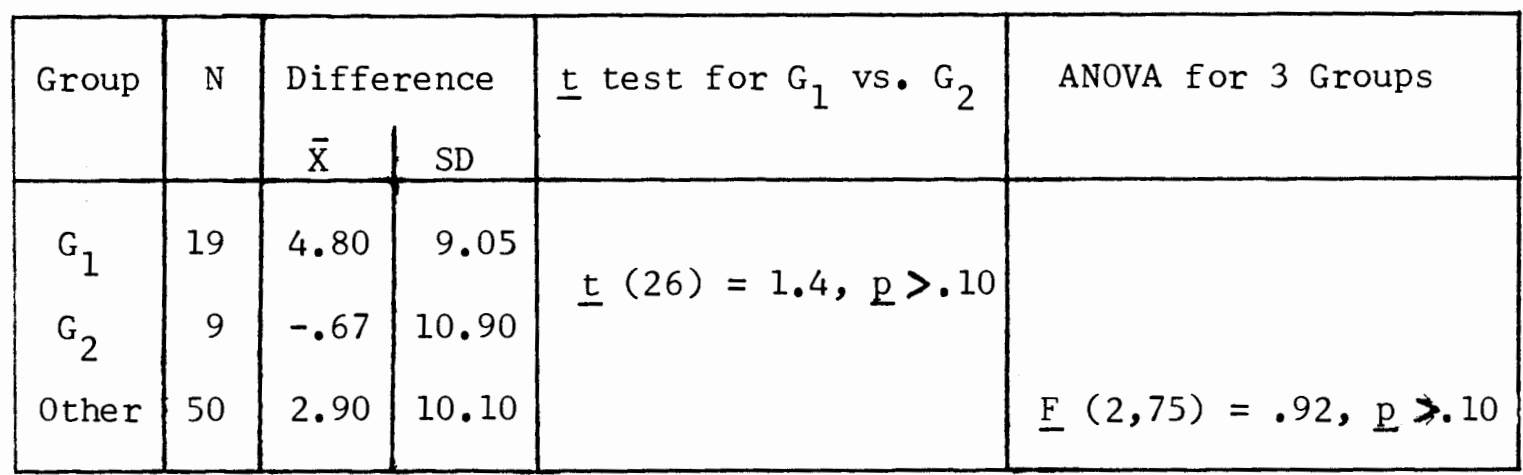

The above statistics indicate that hemisphericity as assessed by CIEM is not related to Verbal-Performance subscale score differences. The hypothesis, therefore, was not supported.

As the subtests object assembly, picture completion, and block design are most unilaterally right hemisphere process tasks, the scale scores of these subtests were summed individually and collectively for each subject in $G_{1}$ and $G_{2}$. The data were analyzed by $t$ tests for a difference between two independent means to assess the expected relationship between right hemisphere orientation and these most purely right hemisphere subtests. The means, standard deviations and $\underline{t}$ values are presented in Tables II, III, IV, and V. Hemispheric orientation was not shown to relate in a significant manner to the subtests individually or collectively at a.10 alpha level. These subjects, therefore, did 
equally well on the right hemisphere tasks regardless of their individual orientation.

TABLE II

SUMMARY OF COMPOSITE DATA AND ANALYSES FOR OBJECT ASSEMBLY, BLOCK DESIGN, AND PICTURE COMPLETION

\begin{tabular}{|c|c|c|c|l|}
\hline Group & $N$ & \multicolumn{2}{|c|}{$\begin{array}{c}\text { Subtest Data } \\
\bar{X}\end{array}$} & SD \\
\hline$G_{1}$ & 19 & 37.7 & 6.0 & test for $G_{1}$ vs. $G_{2}$ \\
$G_{2}$ & 9 & 37.9 & 7.9 & $\underline{t}(26)=.074, \underline{p}>.10$ \\
\hline
\end{tabular}

TABLE III

SUMMARY OF PICTURE COMPLETION DATA AND ANALYSES

\begin{tabular}{|c|c|c|c|c|}
\hline Group & $\mathrm{N}$ & $\begin{array}{c}\text { Subte } \\
\overline{\mathrm{X}}\end{array}$ & $\begin{array}{l}\text { Data } \\
\text { SD }\end{array}$ & $\underline{t}$ test for $G_{1}$ vs. $G_{2}$ \\
\hline $\begin{array}{l}G_{1} \\
G_{2}\end{array}$ & 19 & $\begin{array}{l}12.40 \\
11.67\end{array}$ & $\begin{array}{l}2.80 \\
3.61\end{array}$ & $\underline{t}(26)=-.59, \underline{p}>.10$ \\
\hline
\end{tabular}

TABLE IV

SUMMARY OF BLOCK DESIGN DATA AND ANALYSES

\begin{tabular}{|l|l|c|c|l|}
\hline Group & $N$ & \multicolumn{2}{|c|}{ Subtest Data } & t test for $G_{1}$ vs. $G_{2}$ \\
\hline$G_{1}$ & 19 & 13.10 & 2.60 & SD $(26)=-.24, p>.10$ \\
$G_{2}$ & 9 & 12.80 & 4.02 & $\underline{x}$ \\
\hline
\end{tabular}


TABLE V

SUMMARY OF OBJECT ASSEMBLY DATA AND ANALYSES

\begin{tabular}{|c|c|c|c|c|}
\hline Group & $\mathrm{N}$ & $\begin{array}{c}\text { Subte } \\
\overline{\mathrm{X}} \\
\end{array}$ & $\begin{array}{l}\text { Data } \\
\text { SD }\end{array}$ & $\underline{t}$ test for $G_{1}$ vs. $G_{2}$ \\
\hline $\begin{array}{l}\mathrm{G}_{1} \\
\mathrm{G}_{2}\end{array}$ & $\begin{array}{r}19 \\
9\end{array}$ & $\begin{array}{l}12.20 \\
13.40\end{array}$ & $\begin{array}{r}2.50 \\
1.50\end{array}$ & $\underline{t}(26)=1.4, \underline{p}>.10$ \\
\hline
\end{tabular}

Neither hypothesis relating hemisphericity, as assessed by CLEM, to WISC-R Verbal-Performance subscale differences or the object assembIy, picture completion, and block design subtests was supported for a group of normal children whose IQ's as a whole fall into the high average category as shown in Table VI. The children's full-scale scale scores ranged from a low of 103 to a high of 152 which converts to an IQ score of 101 or average intelligence to 139 or very superior intelligence. None of the children in $G_{1}$ or $G_{2}$ fell below average intelligence. 
TABLE VI

DISTRIBUTION OF SCALE SCORES

\begin{tabular}{|c|c|c|c|c|c|c|c|c|c|}
\hline$G_{1} S$ & Age & FS & V & $\mathrm{P}$ & $G_{2} S$ & Age & FS & V & $\mathrm{P}$ \\
\hline 1 & 14 & 109 & 68 & 41 & 1 & 11 & 112 & 54 & 58 \\
\hline 2 & 13 & 121 & 60 & 61 & 2 & 13 & 103 & 60 & 43 \\
\hline 3 & 12 & 140 & 73 & 67 & 3 & 9 & 151 & 75 & 76 \\
\hline 4 & 9 & 126 & 69 & 57 & 4 & 9 & 122 & 55 & 67 \\
\hline 5 & 13 & 142 & 74 & 68 & 5 & 11 & 128 & 62 & 66 \\
\hline 6 & 12 & 130 & 61 & 69 & 6 & 10 & 132 & 72 & 60 \\
\hline 7 & 10 & 111 & 55 & 56 & 7 & 14 & 107 & 58 & 49 \\
\hline 8 & 10 & 138 & 68 & .70 & 8 & 11 & 138 & 63 & 75 \\
\hline 9 & 11 & 115 & 61 & 54 & 9 & 11 & 107 & 48 & 59 \\
\hline 10 & 11 & 114 & 52 & 62 & & & & & \\
\hline 11 & 9 & 132 & 68 & 64 & & & & & \\
\hline 12 & 9 & 106 & 55 & 51 & & & & & \\
\hline 13 & 12 & 152 & 75 & 77 & & & & & \\
\hline 14 & 10 & 136 & 73 & 63 & & & & & \\
\hline 15 & 9 & 136 & 74 & 62 & & & & & \\
\hline 16 & 8 & 120 & 60 & 60 & & & & & \\
\hline 17 & 9 & 140 & 69 & 71 & & & & & \\
\hline 18 & 13 & 111 & 65 & 46 & & & & & \\
\hline 19 & 10 & 118 & 64 & 54 & & & & & \\
\hline \multicolumn{2}{|l|}{ Mean } & 126 & 66 & 61 & & & 122 & 61 & 61 \\
\hline \multicolumn{2}{|c|}{ Std. Dev. } & 13 & 7 & 9 & & & 16 & 9 & 11 \\
\hline
\end{tabular}




\section{CONCLUSIONS AND RECOMMENDATIONS}

The results of the present study do not show a relationship between WISC-R subscale differences and brain hemisphere orientation as assessed by conjugate lateral eye movements. Neither does the present study demonstrate a relationship between hemisphere orientation, as measured by CLEM, and the subtests object assembly, picture completion, and block design as was expected. Therefore, the present study is in agreement with the Wener and Templer (1976) replication study which did not find a relationship between learning disabled children and WISC Verbal-Performance differences. The present study does not provide any evidence to suggest the WISC-R subscales are related to hemisphericity in normal children.

It should be noted, however, that the subjects utilized in the present study were of higher than average intelligence (see Table VI) and socio-economic backgrounds. The subjects were children of successful, professional people attending a small school district with small class sizes in an economically elite area of Portland, Oregon. The resultant cultural and intellectual stimulation awarded these children is doubtlessly above the societal norm and may have covered up the ability of the WISC-R to detect hemisphericity. Furthermore, the observations of eye movements during administration of the WISC-R necessitated more observations being recorded for left hemisphere 
process questions as the children tended to look directly at the performance problems rather than to make eye movements. The tendency of eye-movement direction to respond to type of question asked may well have influenced the overall data and therefore, the results of the present study and may explain the failure to support the hypotheses. Or, it may be, as Kinsbourne (1982) suggests, that the lack of significant differences in the present study are due to the brain being a highly integrated organ. The research which found relationships between hemisphere functioning and the WISC-R subscales used subjects with known brain dysfunctions, e.g., learning disabled children (Rourke \& Telegdy, 1971; Rourke, Young, \& Flewelling, 1971; Wener \& Templer, 1976) or hemiplegic children (Kershner \& King, 1974) whose brains are probably not able to function in the integrated manner of a normal child. These studies, one could assume, provide the highest chance of showing a significant difference and accepting a false positive result which, although true for these children, is not generalizable to the normal population or the normal uses of the WISC-R.

In the present study, using normal children with most being high average in intelligence, the integration of the hemispheres could be responsible for the lack of subscale score differences between right and left hemisphere oriented children. Since most of the WISC-R Verbal and Performance subtests utilize both hemispheres for adequate problem solving, it would seem that in themselves they negate any differences possibly present in left and right hemisphere oriented children. Viewed in this perspective, one would not expect normally functioning children to manifest subscale score differences of any significance. 
Although not feasible in the present study, further research in this area may benefit from videotaping the eye movements, using a separate list of questions to assess hemisphericity, and perhaps using separate experimenters for the WISC-R testing and eye-movement observations. Also, since all experimenters in the present study were female, the effect of sex of the experimenter is unknown. Random selection and assignment to experimenters would decrease design-dictated biases. Also, as a larger majority of adults demonstrate hemisphericity than do children, it may be advantageous to compare Wechsler Intelligence Scale for Adults--Revised subscale scores and hemispheric orientation utilizing the above suggestions. Since adults seem to be more stablized in their thinking styles, Verbal-Performance differences may be apparent which remain diffuse in children.

Despite the limitations, the experimenter considers the results of the present study relevant to the research in this area. A replication utilizing the above recommendations would provide a more rigorous test of the ability of the WISC-R to detect brain hemisphericity. If the replication should prove negative, further research in this area would seem unpromising. 


\section{REFERENCES}

Bakan, Paul 1969. "Hypnotizability, Laterality of Eye-Movements and Functional Brain Asymmetry," Perceptual and Motor Skills, 28, 927-932.

Bakan, Paul 1971. "The Eyes Have It," Psychology Today, Apri1, 64, $66-67,96$.

Bakan, Paul and Floyd F. Stayer 1973. "On Reliability of Conjugate Lateral Eye Movements," Perceptual and Motor Skills, 36, 429-430.

Bogen, Joseph E. 1969. "The Other Side of the Brain I: Dysgraphia and Dyscopia Following Cerebral Commissurotomy," Bulletin of the Los Angeles Neurological Societies, 34(2), 73-105.

Bruning, James L. and B. L. Kintz 1977. Computational Handbook of Statistics, Glenview, IL: Scott, Foresman and Company.

Day, Merle E. 1964. "An Eye Movement Phenomenon Relating to Attention, Thought and Anxiety," Perceptual and Motor Ski11s, 19, 443-446.

Duke, J. D. 1968. "Lateral Eye Movement Behavior," The Journal of General Psychology, 78, 189-195.

Etaugh, Claire F. 1972. "Personality Correlates of Lateral Eye Movement and Handedness," Perceptual and Motor Skills, 34, 751-754.

Galin, David 1974. "Implications for Psychiatry of Left and Right Cerebral Specialization: A Neurophysiological Context for Unconscious Processes," Archives of General Psychiatry, 12, 572-583.

Galin, David and Robert Ornstein 1974. "Individual Differences in Cognitive Style--I. Reflective Eye Movements," Neuropsychologia, $12,367-376$.

Gazzaniga, M. S. 1970. The Bisected Brain, New York, NY: AppletonCentury-Crofts.

Kaufman, Alan S. 1979a. Intelligent Testing with the WISC-R, New York, NY: John Wiley and Sons.

Kaufman, Alan S. 1979b. "Cerebral Specialization and Intelligence Testing," Journal of Research and Development in Education, 12(2), 96-106. 
Kershner, John R, and Audrey J. King 1974. "Laterality of Cognitive Functions in Achieving Hemiplegic Children," Perceptual and Motor Skills, 39, 1283-1289.

Kinsbourne, Marcel 1972. "Eye and Head Turning Indicates Cerebral Lateralization," Science, 176, 539-541.

Kinsbourne, Marcel 1982. "Hemispheric Specialization and the Growth of Human Understanding," American Psychologist, 37(4), 411-420.

Kocel, Katherine, David Galin, Robert Ornstein, and Edward L. Merrin 1972. "Lateral Eye Movement and Cognitive Mode," Psychonomic Science, $27(4), 223-224$.

Reynolds, Cecil R. and Alan S. Kaufman 1980. "Lateral Eye Movement Behavior in Children," Perceptual and Motor Skills, 50, 1023-1037.

Rourke, Byron P. and Gabor A. Telegdy 1971. "Lateralizing Significance of WISC Verbal-Performance Discrepancies for 0lder Children With Learning Disabilities," Perceptual and Motor Skills, 33, 875-883.

Rourke, B. P., G. C. Young, R. W. Flewelling 1971. "The Relationships Between WISC Verbal-Performance Discrepancies and Selected Verbal, Auditory-Perceptual, Visual-Perceptual, and Problem-Solving Abilities in Children With Learning Disabilities," Journal of Clinical Psychology, 27, 475-579.

Weiten, Wayne and Claire F. Etaugh 1973. "Lateral Eye Movement as Related to Verbal and Perceptual-Motor Skills and Values," Perceptual and Motor Skills, 36, 423-428.

Wener, Brian and Donald I. Templer 1976. "Relationship Between WISC Verbal-Performance Discrepancies and Motor and Psychomotor Abilities of Children With Learning Disabilities," Perceptual and Motor Skills, 42, 125-126. 


\section{APPENDIX}

\section{PARENTAL PERMISSION LETTER}

The following letter was sent to the parents of the entire fourth through eighth grade population of Riverdale School District:

We invite all fourth through eighth grade Riverdale students to be included among 80 who will be randomly selected to participate in a Master's thesis research study. The study has the approval of Dr. Offenbacher and the Riverdale School fourth through eighth grade faculty. The purpose of this study is to document the ability of a standard assessment tool to show the style of processing a child uses when thinking or learning. For instance, some children use a creative, holistic style of thinking while other children use a more analytic, logical style of thinking.

If selected to participate in the research, your child will be given the Wechsler Intelligence Scale for Children-Revised in a one hour session with either myself or one of my assistants. The session will occur in your child's school during school hours. The research will begin as soon as possible. It will take approximately 9 weeks to see each child.

Information resulting from the scale will be available through the school district office or by contacting me personally. Nothing will be placed in your child's file unless you so request. Your child's privacy and confidentiality will be strictly maintained throughout and following 
the research study.

Please feel free to contact Dr. Offenbacher (636-4511) or me with questions in regard to your child's participation in the study:

Robin Hayden

Principal Investigator

1230 SE 26 th 非 6

Portland, OR 97214

(503) 235-0556.

/s/ Robin Hayden

/s/ Claude Offenbacher, Ed.D.

If you wish to have your child included in the random selection of participants in this study, please complete and sign the consent form below. Detach and return it in the enclosed stamped envelope as soon as possible. Thank you.

I do/do not give my consent for my child, (circle one)

(child's name)

to be among those from whom 80 will be randomly selected to participate

in a research study that will involve only their taking the wechsler Intelligence Scale for Children-Revised.

Date

Signed

Parent or Legal Guardian

Please mail to Robin Hayden at the address above or return to Dr. Offenbacher at Riverdale School. 